\title{
Monitoring Hydrotreating Catalysts Synthesis and Deactivation using Raman Spectrometry
}

\author{
M. Digne ${ }^{1}$, K. Marchand ${ }^{1}$ and P. Bourges' \\ 1 Institut français du pétrole, IFP Lyon, BP 3, 69390 Vernaison cedex - France \\ e-mail: mathieu.digne@ifp.fr - karin.marchand@ifp.fr - patrick.bourges@ifp.fr
}

Résumé - Suivi de la synthèse et de la désactivation des catalyseurs d'hydrotraitement par spectrométrie Raman - La spectrométrie Raman est devenue une technique de caractérisation populaire pour les catalyseurs d'hydrotraitement : elle fournit des informations importantes sur la structure chimique, au cours du cycle de synthèse du catalyseur. Les phénomènes physico-chimiques se déroulant sur la surface du catalyseur peuvent être suivis par cette technique. Cet article décrit quelques exemples où la spectrométrie Raman a permis d'évaluer l'impact de paramètres expérimentaux (choix de précurseurs métalliques, présence d'impureté, influence de la température de calcination, dépôt de coke) sur la structure du catalyseur.

\footnotetext{
Abstract-Monitoring Hydrotreating Catalysts Synthesis and Deactivation using Raman Spectrometry - Raman spectrometry has become a popular characterization technique for hydrotreatment catalysts: it provides important information on chemical structures along all the synthesis cycle, from the impregnation solution to the sulfided catalyst. Aspects of physico-chemical processes taking place on the catalyst surface can be monitored using this technique. This article describes some examples where Raman spectrometry has been used to evaluate the impact of experimental parameters (choice of metallic precursors, presence of impurity, influence of calcination temperature, coke deposit) on the catalyst structure.
} 


\section{INTRODUCTION}

Raman spectrometry has become a popular technique of characterization in numerous fields of application, such as polymers, pharmaceutics or hydrocarbons industry $[1,2]$. Thanks to technical advances in instrumentation, like monochromatic intense laser excitation or efficient line rejection systems, Raman spectrometer is now a common equipment in laboratories. In heterogeneous catalysis, Raman spectrometry is widely used to characterize the active surface species on the catalyst. As vibrational spectroscopy, Raman analysis provide information about the chemical structure of the probed species. The obtained data are often complementary to those obtained from other surface characterization techniques, such as XPS or EXAFS.

In this paper, we briefly describe the basis of Raman spectrometry and explain why this method is a powerful tool to analyze hydrotreatment catalysts. Next, we give some examples where Raman spectrometry has been used to improve the description of catalyst structure:

- the speciation of metal atoms during catalyst synthesis,

- the impact of precursor purity on the achieved catalyst,

- the choice of the calcination temperature to avoid inactive phase formation,

- the monitoring of coke deposit on the catalyst surface.

\section{RAMAN SPECTROMETRY AND HETEROGENEOUS CATALYSIS}

Raman spectrometry is based on the Raman effect, predicted by Smekal in 1923 [3] and experimentally observed by Raman and Krishnan in 1928 [4]. When a sample is submitted to a monochromatic light of frequency $v_{0}$, the main part of the light is elastically scattered with the same frequency $v_{0}$ (Rayleigh diffusion). Weakly intense scattered light quanta with frequencies different from those of the incident light quantum, are observed too: their frequencies are equal to $v_{0}+v_{i}$ (anti-Stokes Raman diffusion) and to $v_{0}-v_{i}$ (Stokes Raman diffusion), where $v_{i}$ corresponds to the characteristic vibrational frequency of sample components (molecules or crystals). Raman spectroscopy is thus a vibrational spectroscopy, like infrared spectroscopy.

In term of spectra, the main difference between the two techniques concerns the intensities of the vibrational bands. In infrared adsorption, a vibrational mode will be IR active (i.e., its intensity is not equal to zero), if the corresponding atomistic movement induces a variation of the molecular dipole moment. For instance, the stretch of heteropolar molecules (such as $\mathrm{HCl}$ or $\mathrm{CO}$ ) is IR active. On the contrary, a vibrational mode is Raman active, if the corresponding atomistic movement induces a variation of the molecular polarisability. The stretch of homopolar molecules (such as $\mathrm{H}_{2}$ or $\mathrm{O}_{2}$ ) is Raman active. For small molecules, point group theory allows to determine if a vibrational mode is
Raman (or IR) active or not. The example of benzene molecule is famous: all Raman active modes are IR inactive, and inversely. This property demonstrates that the benzene molecule is centro-symmetric. For larger molecules or for ill crystallized solids, there is no simple rule to determine the relative intensities but Raman and Infra Red spectra are often complementary to determine the sample structure.

For liquid sample, the choice between Raman and IR spectroscopy strongly depends on the solvent. In IR adsorption, the study of solutes in aqueous solution is difficult due to the high absorption of water. Solutes IR bands are difficult to observe among those of water solvent. On the contrary, water exhibits a poorly intense signal in Raman spectrometry. In a similar way, analyzing compounds deposited on a solid support, the choice between both techniques depends on the support response. For instance, alumina exhibits intense IR bands between 400 and $1300 \mathrm{~cm}^{-1}$. If the surface species present bands in this spectral region, it will be easier to analyse them using Raman spectrometry. One practical advantage of Raman analysis is that no sample pre-treatment is usually required. However, Raman spectrometry exhibits limitations, mainly due to the inherently small intensity of the Raman signal. First, the technique is not sensitive: to give orders of magnitude, bands are detectable for concentrations greater than $0.01 \mathrm{~mol} \cdot \mathrm{L}^{-1}$ for liquid sample and greater than 1 weight percent for solid sample. Next, fluorescence phenomena, often due to impurities, are several order of magnitude more intense than Raman signal and can mask the Raman spectra. Of course, approaches exist to

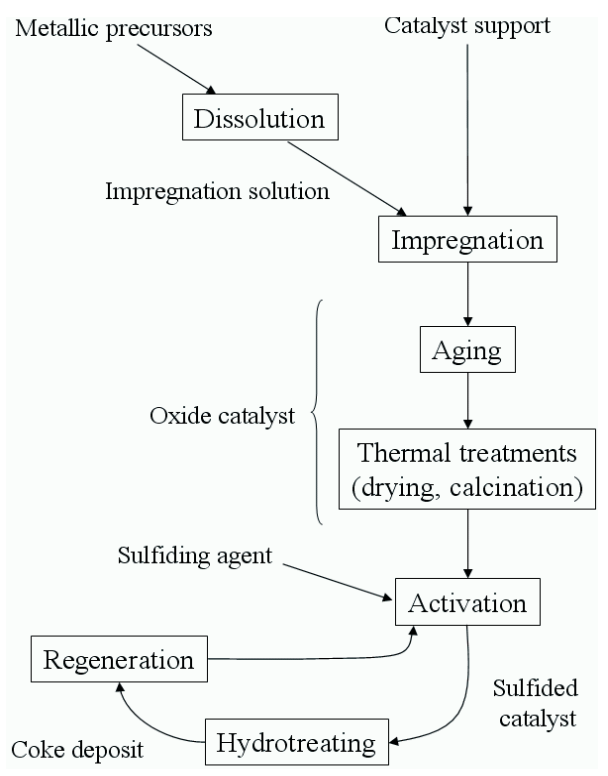

Figure 1

Different steps of hydrotreating catalyst synthesis and life. 
overcome these difficulties (for instance, Surface-Enhanced Raman Spectroscopy, or Resonance Raman Spectroscopy to increase the sensitivity), but their uses remains technically limited.

Industrial hydrotreatment catalysts are molybdenum- or tungsten-based catalysts, promoted by nickel or cobalt. These active components are dispersed on the surface of an oxide support, commonly $\gamma$-alumina or silica-alumina. At industrial scale, the support is a preformed material (pellet, extrudate...). Numerous pathways exist to prepare supported catalysts and each pathway is a sequence of elementary steps [5]. Standard procedure for hydrotreating catalyst preparation is given in Figure 1: the precursors of the active phase, metallic salt or oxide, are dissolved in water to form the impregnation solution. Some additives, such as orthophosphoric acid [6], can be added to increase metal solubility and/or to modify the chemical properties of the solution. The deposit of metal on the support is commonly performed using the incipient wetness impregnation: a volume of solution equal to the pore volume of the support is contacting with the support. The metallic species diffuse inside the support and interactions between these species and the support surface site occur. A step of aging can be added, followed by thermal treatments. The procedure of these thermal treatments strongly depends on the nature of the catalyst: usually, the step of drying $\left(100-150^{\circ} \mathrm{C}\right)$ and calcination $\left(300-500^{\circ} \mathrm{C}\right)$ are distinguished. The first one leads to the removal of residual water and the second provides surface species with their final structure. A sulfidation step is required to active the catalyst: in the presence of sulfiding agents (for instance, hydrogen sulfide), oxide phases are converted into sulfided phases, based on $\mathrm{MoS}_{2}$ or $\mathrm{WS}_{2}$ layers. In the HDT plant, coke is deposited on the catalyst surface and tends to deactivate it. At the end of catalyst cycle, the catalyst can be changed or regenerated. Raman spectrometry is a suitable technique to follow the sequential procedure of synthesis. All the solutions are aqueous: it is thus easy to determine the speciation of molybdenum and tungsten. The supports, alumina or silica-alumina, exhibit weak Raman signal. As a consequence, after impregnation, Raman spectra only reveal the bands of Mo- and W-based surface species. In situ characterizations are easy to perform using a cell, equipped with a quartz window. The laser beam is focused and the scattered radiation are collected through the window. No pre-treatment of the sample is usually required before analysis. Finally, Raman microscopy allows to investigate different positions on the catalyst surface: heterogeneity of the catalyst, such as crystalline particles, can be evidenced. The point is particularly interesting for the shaped catalysts. For instance, this feature have been recently used to monitor a pore volume impregnation inside $\mathrm{Al}_{2} \mathrm{O}_{3}$ pellets [7,8]. All these reasons explain the increasing popularity of Raman spectrometry in the field of hydrotreatment catalysis.

\section{EXPERIMENTAL}

\subsection{Synthesis}

Supported catalysts were synthesized using standard preparation methods. The impregnation solutions were prepared by dissolving metallic salts or metallic oxide in aqueous solution. First, the molybdenum or tungsten precursor was dissolved. Phosphoric acid may be added, depending on the required formulation. Next, the Ni or Co promoter precursor was added as hydroxide, nitrate or carbonate salts. The resulting solution was acid ( $\mathrm{pH}$ lower than 3$)$. The supports are $\gamma$-alumina for $\operatorname{CoMo}(\mathrm{P})$ catalysts and silicaalumina (SA) for NiW catalysts. Extrudates were impregnated by the incipient wetness method. The impregnation are followed by drying and calcination. More details for each catalyst will be given in the next sections.

\subsection{Characterization}

Raman spectra are recorded using a Jobin Yvon LamRAM HR spectrometer. The argon laser at $514 \mathrm{~nm}$ is focused on the sample by a microscope. A $\times 50$ objective is used: the size of the spot with such an objective is typically $2 \mu \mathrm{m}$. The back-scattered radiations are collected and the spectral resolution is about $0.5 \mathrm{~cm}^{-1}$. The power of the laser beam is about $4 \mathrm{~mW}$ for aqueous solutions and in the range of 2 to $4 \mathrm{~mW}$ for supported catalysts. The only exception concerns the coke deposit analysis: a lower laser power $(0.4 \mathrm{~mW})$ is applied, in order to avoid structural changes induced by the laser. A $\times 100$ objective allows to obtain high-sensitivity, even for low carbon-content samples. The study in temperature (Sect. 5.2) have been performed using a TS1500 Linkam cell, with a heating rate of $10^{\circ} \mathrm{C} \cdot \mathrm{mn}^{-1}$.

\section{SPECIATION OF ACTIVE COMPONENTS}

Active phases of hydrotreating catalyst are obtained by impregnation of tungstic or molybdic anions. Depending on $\mathrm{pH}$ value, ionic strength and metal concentration, different isopolytungstate $\mathrm{W}_{x} \mathrm{O}_{y}^{z-}$ and isopolymolybdate $\mathrm{Mo}_{x} \mathrm{O}_{y}^{z-}$, exhibiting various structures, are stable in aqueous solution [9]. Moreover, adding phosphorous, numerous heteropolyanions can be synthesized, such as Keggin species $\mathrm{PW}_{12} \mathrm{O}_{40}^{3-}$ or Dawson species $\mathrm{P}_{2} \mathrm{~W}_{18} \mathrm{O}_{62}^{6-}$. Starting from these isopoly- and heteropoly-anions, it is possible to insert additional transition metals into the framework. The $\mathrm{PCoMo}_{11} \mathrm{O}_{39}^{6-}$ anion, for which one Mo atom of the Keggin structure have been replaced by one Co atom, illustrates this idea [10]. A second approach is possible to add transition metal atoms into the structure, by using the metal cation as counter cation in the salt. The $(\mathrm{Co})_{3 / 2}\left(\mathrm{PMo}_{12} \mathrm{O}_{40}\right)$ compound provides an example of this method [11]. This huge versatility of tungstic or molybdic anions offers numerous pathways for the synthesis of hydrotreating catalysts. The 
chemical structure of the supported oxide species strongly affects the catalyst activity. In this context, analytical methods are required to investigate the speciation of active component during the different steps of catalyst synthesis. The structure of Mo-based and W-based molecular species can be easily determined using Raman spectroscopy. Indeed, $\mathrm{Me}-\mathrm{O}$ and $\mathrm{Me}-\mathrm{O}-\mathrm{Me}$ stretches lead to intense bands between 800 and $1000 \mathrm{~cm}^{-1}$. The characteristic bands of isopoly- and heteropoly-anions have been reported in the literature (for instance, in aqueous solutions, see [12] for isopolymolybdate and [13] for isopolytungstate).

Following these principles, Raman spectroscopy has been used as a routine method to follow the tungsten speciation during the synthesis of NiW/SA catalysts. Successive Raman spectra have been recorded: the tungsten precursor, the aqueous solution with the dissolved precursors, the impregnation solution containing nickel promoter and the dried catalyst after impregnation. Two tungsten salts

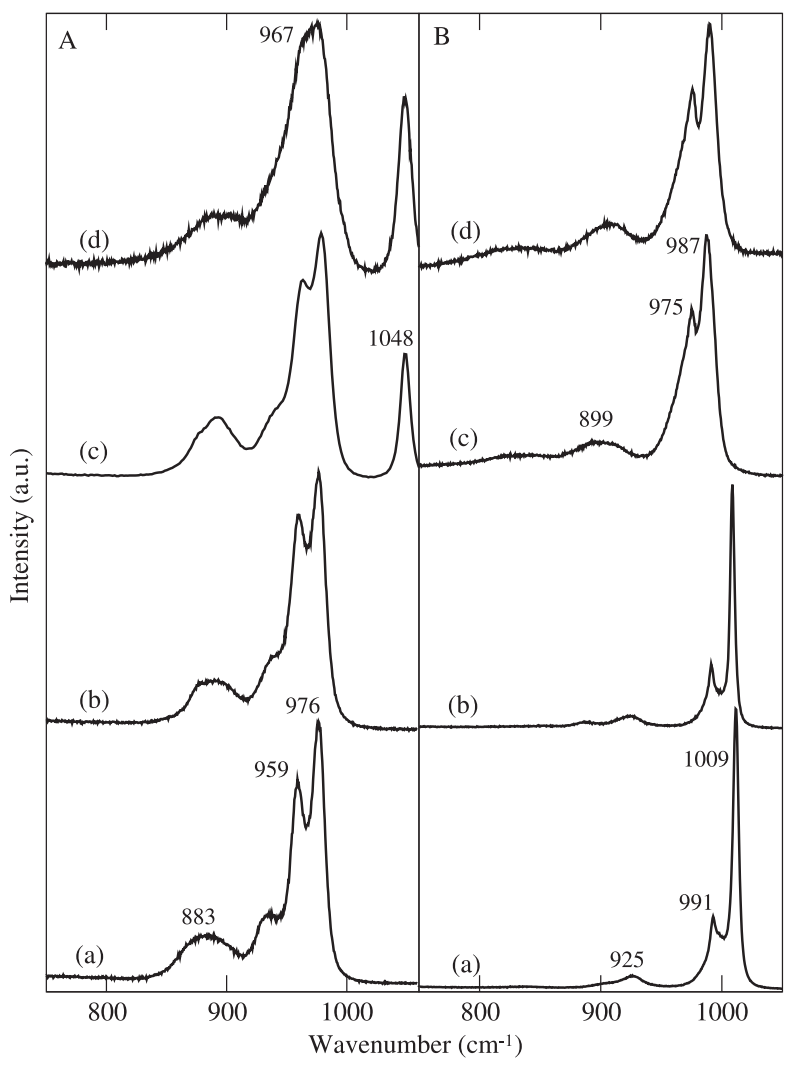

Figure 2

NiW/SA catalysts obtained from two tungsten precursors: (A) $\left(\mathrm{NH}_{4}\right)_{6} \mathrm{H}_{2} \mathrm{~W}_{12} \mathrm{O}_{40} \cdot 4 \mathrm{H}_{2} \mathrm{O}$ and $(\mathrm{B}) \mathrm{H}_{3} \mathrm{PW}_{12} \mathrm{O}_{40} \cdot \mathrm{xH}_{2} \mathrm{O}$. Raman spectra of the different steps of synthesis: (a) tungsten precursor solid, (b) precursor dissolved in water, (c) impregnation solution including Ni promoter and (d) impregnated catalyst after drying.

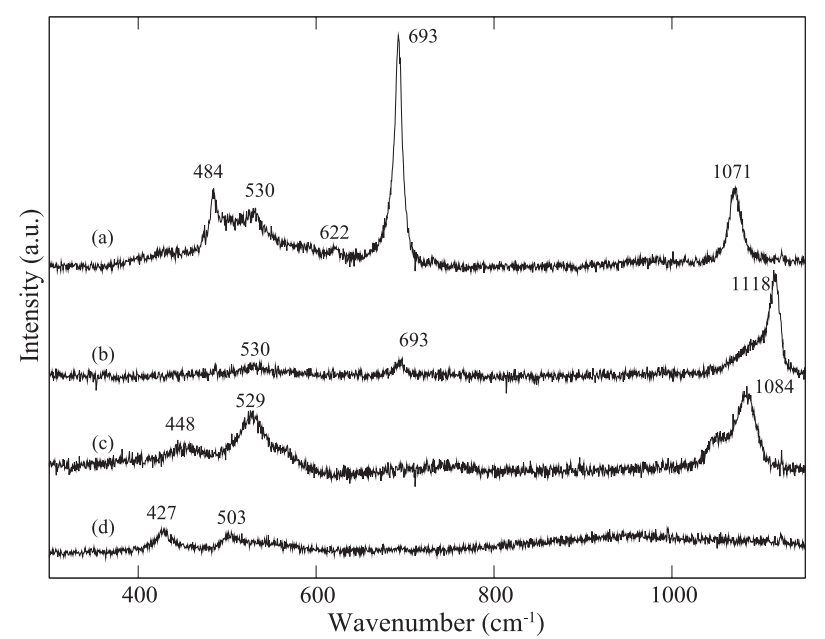

Figure 3

Raman spectra of cobalt(II) carbonates from different suppliers A (a), B (b), C (c) and of cobalt(II) hydroxide (d).

have been used: $\left(\mathrm{NH}_{4}\right)_{6} \mathrm{H}_{2} \mathrm{~W}_{12} \mathrm{O}_{40} \cdot 4 \mathrm{H}_{2} \mathrm{O}$ (Fig. 2a) and $\mathrm{H}_{3} \mathrm{PW}_{12} \mathrm{O}_{40} \cdot \mathrm{xH}_{2} \mathrm{O}$ (Fig. 2b). They exhibit a Keggin structure: twelve $\mathrm{WO}_{6}$ octahedra are arranged in four groups of three edge-shared octahedra, $\mathrm{W}_{3} \mathrm{O}_{13}$. This arrangement generates a central tetrahedral site: two protons take place in this site for $\left(\mathrm{NH}_{4}\right)_{6} \mathrm{H}_{2} \mathrm{~W}_{12} \mathrm{O}_{40} \cdot 4 \mathrm{H}_{2} \mathrm{O}$ and one phosphorous atom occupies this site for $\mathrm{H}_{3} \mathrm{PW}_{12} \mathrm{O}_{40} \cdot \mathrm{xH}_{2} \mathrm{O}$. The two main bands of the $\left(\mathrm{NH}_{4}\right)_{6} \mathrm{H}_{2} \mathrm{~W}_{12} \mathrm{O}_{40} \cdot 4 \mathrm{H}_{2} \mathrm{O}$ solid are found at 959 and $976 \mathrm{~cm}^{-1}$. In acidic solutions, this salt dissolves and the Raman spectra remains unchanged. The $\mathrm{H}_{2} \mathrm{~W}_{12} \mathrm{O}_{40}^{6-}$ anions is the stable tungsten complex, for $\mathrm{W}$ concentration higher than $0.1 \mathrm{M}$ and for $\mathrm{pH}$ value lower than about 3 . The addition of nickel cation, as nickel(II) nitrate, does not affect the bands: $\mathrm{H}_{2} \mathrm{~W}_{12} \mathrm{O}_{40}^{6-}$ and hydrated $\mathrm{Ni}^{2+}$ ions are the predominant species in the impregnation solution. After impregnation on SA and drying at $120^{\circ} \mathrm{C}$, the shape of the Raman spectra is slightly modified: the main part of tungsten is absorbed on the surface as $\mathrm{H}_{2} \mathrm{~W}_{12} \mathrm{O}_{40}^{6-}$ surface species. Nevertheless, the two main bands are no longer resolved: this result shows that the Keggin structure starts to evolve at $120^{\circ} \mathrm{C}$. The effect of calcination on this catalyst is discussed in Section 5.2.

For the second tungsten precursor, $\mathrm{H}_{3} \mathrm{PW}_{12} \mathrm{O}_{40} \cdot \mathrm{xH}_{2} \mathrm{O}$, the main band is located at $1009 \mathrm{~cm}^{-1}$, with a less intense band at $991 \mathrm{~cm}^{-1}$. The $\mathrm{PW}_{12} \mathrm{O}_{40}^{3-}$ anion is stable after dissolution. But, after addition of nickel cation, as nickel(II) carbonate, the band at $1009 \mathrm{~cm}^{-1}$ disappears and a couple of band at 975 and $987 \mathrm{~cm}^{-1}$ appears. This change indicates that acidification of the solution stabilizes a new species. Its structure is currently not clear, but the bands positions are consistent with the polytungstate $\mathrm{Y}_{-}-\mathrm{W}_{10} \mathrm{O}_{32}^{4-}$. This species exists at $\mathrm{pH}$ value between 1 and 3 and its main bands are 
reported at 972 and $988 \mathrm{~cm}^{-1}$ [13]. Nickel atoms do not interact with the tungsten anion: the UV-Vis spectrum of the impregnation solution reveals hydrated Ni(II) cations. The tungsten species is stable after impregnation on SA support and drying at $120^{\circ} \mathrm{C}$. These two examples show that the speciation of active species evolves during the catalyst synthesis. For liquid and solid samples, Raman spectrometry provides a fast method to follow the speciation and explain the physico-chemical processes responsible for this evolution.

\section{INFLUENCE OF PRECURSORS PURITY}

When one scales up catalyst synthesis from laboratory to plant unit, one important matter is the choice of mineral precursors. Indeed, in the laboratory, catalyst preparation are usually performed using higher purity compounds. In plant, high quantities of products are required and different suppliers provide a given product: the impurities nature and content are often not fully described. For this reason, one has to verify that any impurity impact your catalyst performances.

We illustrate this idea in the case of cobalt feedstock: cobalt is a promoter for hydrodesulfurization $\mathrm{MoS}_{2} / \mathrm{Al}_{2} \mathrm{O}_{3}$ catalyst. Experimentally, a molar ratio $\mathrm{Co} / \mathrm{Mo}$ of 0.5 provides the best promoting effect. Cobalt is usually added in the impregnation solution as cobalt salt: until recently, cobalt(II) nitrate has been commonly used. To avoid NOx exhaust during the calcination step, $\mathrm{Co}\left(\mathrm{NO}_{3}\right)_{2}$ can be replaced by cobalt(II) hydroxide or cobalt(II) carbonate. $\mathrm{Co}(\mathrm{OH})_{2}$ exhibits no problematic counter-ion and carbonates are eliminated as $\mathrm{CO}_{2}$ gas by acidification of the solution. The Raman spectra of three $\mathrm{CoCO}_{3}$ from different providers (quoted as $\mathrm{A}, \mathrm{B}, \mathrm{C}$ ) and one $\mathrm{Co}(\mathrm{OH})_{2}$ have been recorded (Fig. 3). $\mathrm{CoCO}_{3}$ samples exhibit bands at around $1100 \mathrm{~cm}^{-1}$ corresponding to the symmetric stretches of $\mathrm{CO}_{3}^{2-}$ ions: this band for free carbonate ions in water is located at $1066 \mathrm{~cm}^{-1}$. For each sample, the main wavenumber is different $\left(1071,1084\right.$ and $\left.1118 \mathrm{~cm}^{-1}\right)$, showing that their crystallographic structures are different. The cobalt(II) hydroxide is characterized by a wavenumber at $3573 \mathrm{~cm}^{-1}$, due to symmetric $\mathrm{O}-\mathrm{H}$ bond stretch. In the low frequency region, bands due to lattice vibrations and librations are observed. For instance, for $\mathrm{Co}(\mathrm{OH})_{2}$, the bands at 427 and $503 \mathrm{~cm}^{-1}$ and the shoulder at $547 \mathrm{~cm}^{-1}$ allow to identify the $\beta-\mathrm{Co}(\mathrm{OH})_{2}$ phase, exhibiting a brucite-type structure [14]. Another important difference between cobalt carbonate spectra is visible: $\mathrm{CoCO}_{3} \mathrm{~A}$ exhibits an intense band at $693 \mathrm{~cm}^{-1}$ whereas this band is weakly intense for $\mathrm{CoCO}_{3}$ $\mathrm{B}$ and not present for $\mathrm{CoCO}_{3} \mathrm{C}$. This band is assigned to the spinel cobalt oxide $\mathrm{Co}_{3} \mathrm{O}_{4}$ [15]. Other specific bands of this oxide are detectable at 622,530 and $484 \mathrm{~cm}^{-1}$. A qualitative measurement of $\mathrm{Co}_{3} \mathrm{O}_{4}$ content can be performed using a mechanical mixture for the calibration. Nevertheless, it is clear from the relative intensities that the $\mathrm{CoCO}_{3} \mathrm{~A}$ sample exhibits the highest impurity content.
Supported catalysts have been prepared using cobalt carbonate $\mathrm{A}$ and $\mathrm{C}$. Cobalt oxide $\mathrm{Co}_{3} \mathrm{O}_{4}$ is insoluble in water, even at high temperature. As a consequence, $\mathrm{Co}_{3} \mathrm{O}_{4}$ particles are present in the impregnation solution obtained from cobalt carbonate A. After impregnation, the supported catalyst have been investigated using Raman spectroscopy (Fig. 4). For cobalt carbonate $\mathrm{A}$, the $\mathrm{Co}_{3} \mathrm{O}_{4}$ particles are mainly deposited on the external surface of the pellets (Fig. 4a). Even inside the pellets, some positions reveal a band at $687 \mathrm{~cm}^{-1}$ (Fig. $4 \mathrm{c}$ ): the smallest $\mathrm{Co}_{3} \mathrm{O}_{4}$ particles seems to have diffused inside the catalyst pores. For cobalt carbonate $\mathrm{C}$ (Fig. 4 b, d), $\mathrm{Co}_{3} \mathrm{O}_{4}$ crystallites are not detected. As a conclusion, the $\mathrm{Co}_{3} \mathrm{O}_{4}$ impurity modify the catalyst structure by two ways:

- the ideal molar ratio $\mathrm{Co} / \mathrm{Mo}$ of 0.5 is not reached because a part of Co atoms are not involved into the sulfided CoMoS layers;

- the $\mathrm{Co}_{3} \mathrm{O}_{4}$ particles, mainly localized on the external surface, can obstruct pores.

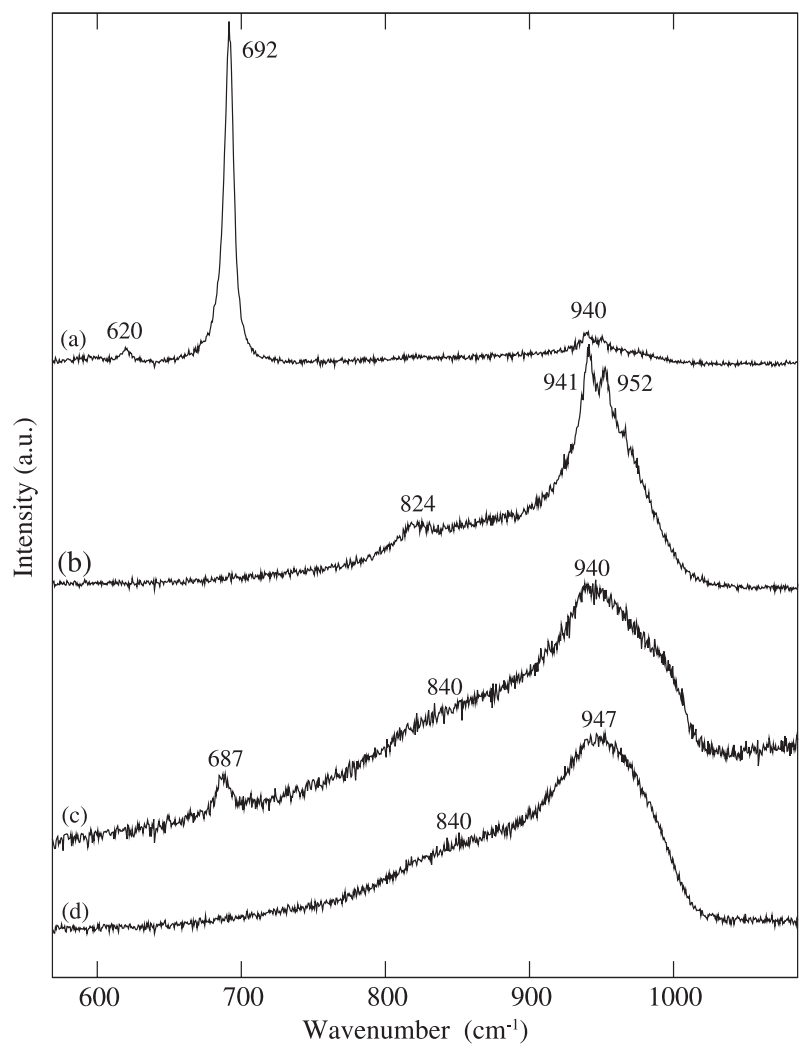

Figure 4

Raman spectra of $\mathrm{CoMo} / \mathrm{Al}_{2} \mathrm{O}_{3}$ catalysts obtained using two different cobalt(II) carbonate as precursors: (a) and (b) external surface of pellets using $\mathrm{CoCO}_{3} \mathrm{~A}$ and $\mathrm{C}$, respectively and (c) and (d) position inside pellets using $\mathrm{CoCO}_{3} \mathrm{~A}$ and $\mathrm{C}$, respectively. 


\section{EFFECT OF CALCINATION TEMPERATURE}

\subsection{CoMoP/ $/ \mathrm{Al}_{2} \mathrm{O}_{3}$ Catalysts}

Calcination is an important step of catalyst synthesis. Indeed, several surface phenomena occur during calcination: decomposition of supported precursors, modification of the interactions between support and active phase, sintering... These changes can lead to the formation of crystalline phases, such as $\mathrm{MoO}_{3}$ or $\mathrm{CoMoO}_{4}$, which are difficult to sulfide and so inactive for HDT. As a consequence, the calcination conditions impact the catalyst activity. Two experimental parameters control the calcination step: the gas atmosphere and the temperature. In the following example, we demonstrate that Raman spectrometry can provide guideline to optimize the calcination conditions.

Starting from the same $\mathrm{CoMoP} / \gamma-\mathrm{Al}_{2} \mathrm{O}_{3}$ dried sample, different calcination temperatures have been applied. After calcination, the catalysts have been transferred in air before analysis. The Raman spectra of different positions inside the catalyst pellets (Fig. 5) show the influence of calcination

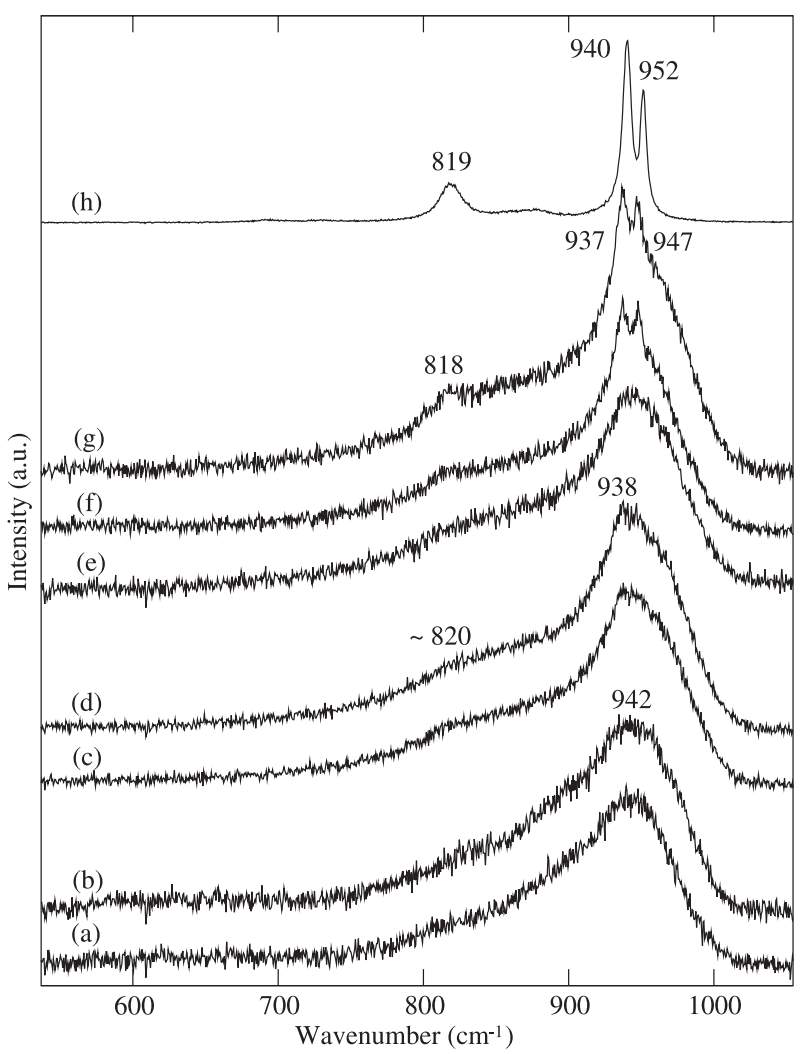

Figure 5

Raman spectra recorded at different positions and for different temperature of calcination: (a) and (b) $+30^{\circ} \mathrm{C}$, (c) and (d) $+330^{\circ} \mathrm{C}$, and (e), (f) and $(\mathrm{g})+390^{\circ} \mathrm{C}$. (h) Raman spectra of $\beta-\mathrm{CoMo}_{4}$.
TABLE 1

Variation of $\mathrm{CoMoO}_{4}$ content as a function of calcination temperature (see text for the definitions)

\begin{tabular}{c|c|c}
\hline $\mathrm{T}_{\text {cal. }}\left({ }^{\circ} \mathrm{C}\right)$ & $\mathrm{CoMoO}_{4}(\%)$ & $\Delta(\%)$ \\
\hline+30 & 3 & 2 \\
+330 & 22 & 7 \\
+390 & 43 & 13 \\
\hline
\end{tabular}

temperature on the structure of the active phases. For a calcination temperature $30^{\circ} \mathrm{C}$ higher than the drying temperature (quoted as $+30^{\circ} \mathrm{C}$ ), the catalyst appears as spatially homogeneous. Whatever the position explored, similar Raman spectra have been obtained: an intense asymmetric band, centered at $942 \mathrm{~cm}^{-1}$, with a strong shoulder at lower frequency. This shape is standard for dried catalysts $[16,17]$ and can be assigned to $\mathrm{P}_{2} \mathrm{Mo}_{5} \mathrm{O}_{23}^{6-}$ (main band at $942 \mathrm{~cm}^{-1}$ in aqueous solution), to $\mathrm{Mo}_{7} \mathrm{O}_{24}^{6-}$ (main band at $941 \mathrm{~cm}^{-1}$ in aqueous solution), or to a mixture of these two species [7]. For calcination temperatures between +30 and $+280^{\circ} \mathrm{C}$, the Raman spectra do not evolve and are representative of dried CoMoP surface species. For higher calcination temperatures, the Mo and Co surface species can sinter in order to form $\mathrm{CoMoO}_{4}$ crystal particles. The Raman spectrum of $\beta-\mathrm{CoMoO}_{4}$ (Fig. $5 \mathrm{~h}$ ) is characterized by two strong bands at 940 and $952 \mathrm{~cm}^{-1}$, and a less intense band at $819 \mathrm{~cm}^{-1}$. This fingerprint is observed on the catalyst calcined at $+390^{\circ} \mathrm{C}$ (Fig. 5g, f). It is interesting to note that the thermodynamically stable structure is $\alpha-\mathrm{CoMoO}_{4}$, exhibiting a single Raman band located at $938 \mathrm{~cm}^{-1}$ [18]. Nevertheless, on $\gamma-\mathrm{Al}_{2} \mathrm{O}_{3}$ support, the $\beta-\mathrm{CoMoO}_{4}$ structure is the stable polymorph at high temperature. Moreover, the catalyst appears as inhomogeneous from the Raman point of view. Indeed, for some positions (Fig. 5e), the Raman spectra is close to the spectra of the catalyst calcined at $+30^{\circ} \mathrm{C}$. Finally, for $+330^{\circ} \mathrm{C}$, the catalyst seems homogeneous. The Raman spectra shape (Fig. $5 g, f$ ) is close to the catalyst obtained at $+30^{\circ} \mathrm{C}$, but shoulders at about 820 and $938 \mathrm{~cm}^{-1}$ indicates the formation of $\beta-\mathrm{CoMoO}$ particles.

In order to give more quantitative results to this transformation, a simple model has been developed. The details of this model will be given in a future article. Briefly, we assume that, whatever the temperature, the Raman spectrum is described by a linear combination of the spectrum of supported $\beta-\mathrm{CoMoO}_{4}$ and dried CoMoP surface species. As a reference, an over-calcined catalyst is used for supported $\beta-\mathrm{CoMoO}_{4}$ and a dried catalyst is used for dried CoMoP surface species. After normalization, Raman spectra are fitted between 529 et $1059 \mathrm{~cm}^{-1}$ according to the linear combination of spectra:

$$
\mathrm{S}(\text { sample })=\alpha \mathrm{S}\left(\mathrm{CoMoO}_{4}\right)+\beta \mathrm{S}(\operatorname{driedCoMo})
$$

In all cases, the relative differences between simulated and experimental spectra is lower than $5 \%$, which validates 


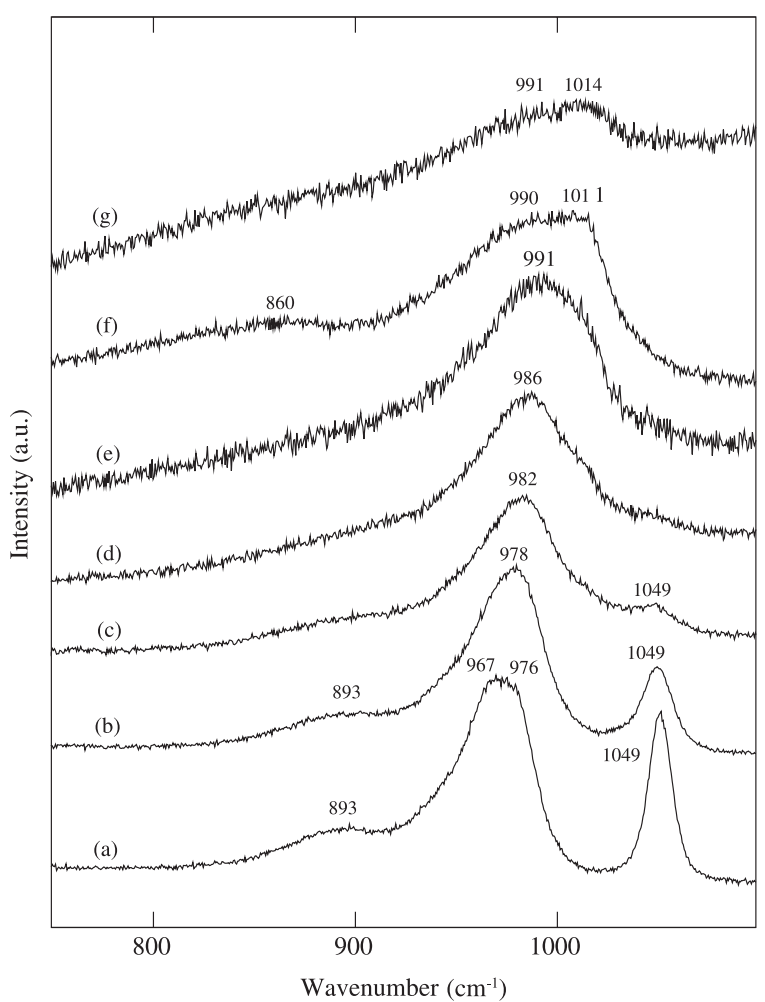

Figure 6

Raman spectra of NiW/SA catalyst recorded under $\mathrm{N}_{2}$ flow and at different temperature: (a) $20^{\circ} \mathrm{C}$, (b) $60^{\circ} \mathrm{C}$, (c) $120^{\circ} \mathrm{C}$, (d) $180^{\circ} \mathrm{C}$, (e) $240^{\circ} \mathrm{C}$, (f) $350^{\circ} \mathrm{C}$ and (g) $450^{\circ} \mathrm{C}$.

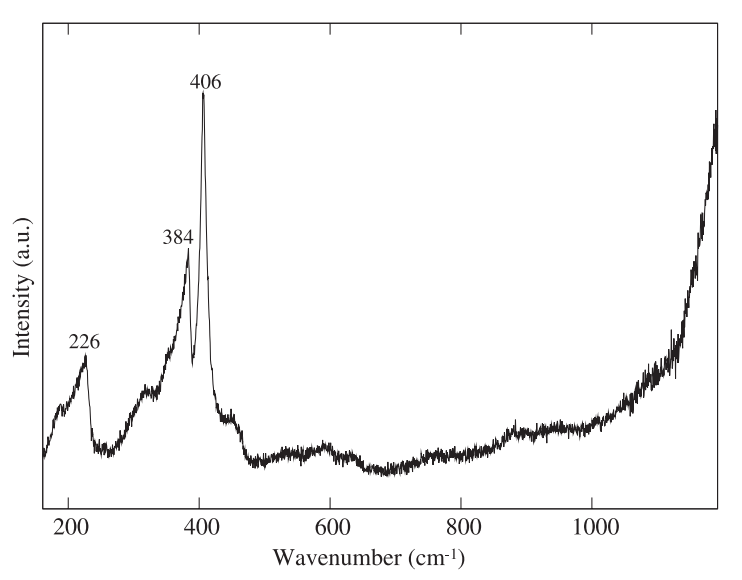

Figure 7

Raman spectra of industrial unit used $\mathrm{NiMo} / \mathrm{Al}_{2} \mathrm{O}_{3}$ catalyst: low frequencies region.

the model. We calculate the $\mathrm{CoMoO}_{4}$ content defined as the ratio between surface species quantity, $\alpha /(\alpha+\beta)$. The given value is an average over the spectra of the different explored positions. The relative standard deviation of the measured $\mathrm{CoMoO}_{4}$ content, quoted as $\Delta$, is related to the surface heterogeneity at the $\mu \mathrm{m}$ scale. The results (Table 1) confirm the qualitative analysis: between +330 and $+350^{\circ} \mathrm{C}$, the $\mathrm{CoMoO}_{4}$ content is multiplied by two and the catalyst surface becomes inhomogeneous: the $\mathrm{CoMoO}_{4}$ particles start to sinter.

\subsection{NiW/SA Catalyst}

The calcination of supported catalysts can be followed in situ using an appropriate cell. In this section, the calcination of NiW/SA catalyst, obtained from $\left(\mathrm{NH}_{4}\right)_{6} \mathrm{H}_{2} \mathrm{~W}_{12} \mathrm{O}_{40} \cdot 4 \mathrm{H}_{2} \mathrm{O}$ and $\mathrm{Ni}\left(\mathrm{NO}_{3}\right)$ precursors, have been studied. An in situ treatment has been performed in the cell: spectra at different temperature from 20 to $450^{\circ} \mathrm{C}$, under $\mathrm{N}_{2}$ flow have been recorded (Fig. 6). Increasing the temperature, a fluorescence background appears and tends to mask the Raman spectra. First, nitrate ions, absorbed on the surface, are removed: their band at $1049 \mathrm{~cm}^{-1}$ completely disappears at $180^{\circ} \mathrm{C}$. The temperature increase modifies the active phase spectrum. At $60^{\circ} \mathrm{C}$, a single broad band is observed and its frequency increases with the temperature, from $978 \mathrm{~cm}^{-1}$ at $60^{\circ} \mathrm{C}$ to $991 \mathrm{~cm}^{-1}$ at $450^{\circ} \mathrm{C}$. Raman wavenumbers are usually downshifted with an increase of temperature, due to the anharmonicity of the potential. As a consequence, an increase of the frequency reveals a structural modification: the cluster size of tungsten surface species probably increases with temperature. This phenomena have been already observed for $\mathrm{WO}_{x} / \mathrm{ZrO}_{2}$ [19]. At $240^{\circ} \mathrm{C}$, a shoulder appears at about $1010-1015 \mathrm{~cm}^{-1}$. This band grows with temperature and becomes as intense as the band at $990 \mathrm{~cm}^{-1}$ at $350^{\circ} \mathrm{C}$. The band could be assigned to a second kind of tungsten surface species, exhibiting a specific structure. As a consequence, the nature and the size of tungsten surface species highly depend on the calcination temperature.

\section{USED CATALYSTS CHARACTERIZATION}

Raman spectrometry have been widely applied to the study of used catalysts (for instance, see [20-22]). Two linked phenomena are responsible for the catalyst deactivation: the structural evolution of the active phase and the deposit of carbonaceous compounds on the catalyst surface. The chemical nature of this deposit depends on the feedstock molecules, which react to form coke. In this section, we briefly describe what kind of information about catalyst deactivation can be extracted from Raman spectra.

The Raman spectra of the $\mathrm{NiMo} / \mathrm{Al}_{2} \mathrm{O}_{3}$ catalyst, used during two years in a gasoil hydrodesulfurization unit, exhibits two low-wavenumber bands at 384 and $406 \mathrm{~cm}^{-1}$ (Fig. 7). These bands are characteristic of $\mathrm{MoS}_{2}$ phase (reported at 384 and $409 \mathrm{~cm}^{-1}$ for the $\mathrm{MoS}_{2}$ crystal [23]). No band between 800 and $1000 \mathrm{~cm}^{-1}$, corresponding to the Mo-O stretches region, is observed: this means that partial 


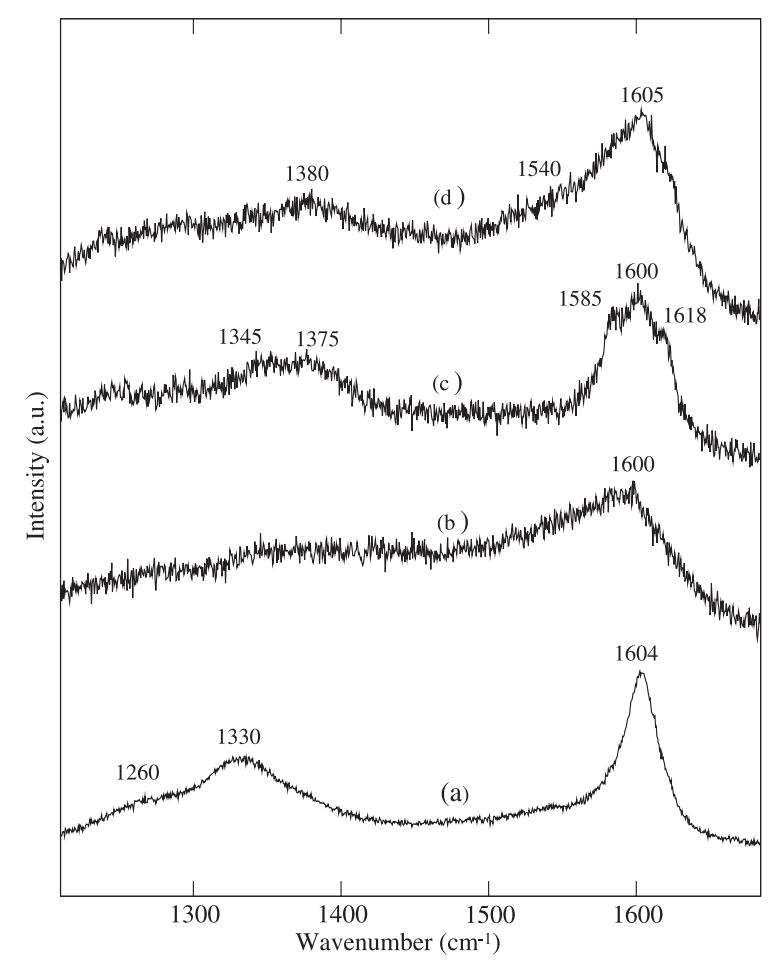

Figure 8

Raman spectra of used $\mathrm{NiMo} / \mathrm{Al}_{2} \mathrm{O}_{3}$ catalysts (industrial unit catalyst (a) and pilot-scale unit catalysts (b), (c) and (d)): characteristic bands of deposited coke.

reoxidation of $\mathrm{MoS}_{2}$ layers does not occur. The superficial coke layer stabilize the sulfided phase and prevent the oxidation by air: this remark is general for used HDT catalysts.

Between 1200 and $1700 \mathrm{~cm}^{-1}$, coke deposit exhibits two groups of bands (Fig. $8 a$ ) the first one is located between 1550 and $1650 \mathrm{~cm}^{-1}$ and the second one, usually less intense and broader, between 1250 and $1450 \mathrm{~cm}^{-1}$. Moreover, this shape is analogous to the spectrum of graphite: a band at about $1585 \mathrm{~cm}^{-1}$ ( $\mathrm{G}$ mode) and a less intense one at $1355 \mathrm{~cm}^{-1}$ (D mode). These bands mainly correspond to the ring stretchings of fused-ring aromatic molecules. The precise fingerprint of coke strongly depends of feedstock and deactivation conditions. Using pilot-scale units, the same $\mathrm{NiMo} / \mathrm{Al}_{2} \mathrm{O}_{3}$ catalyst has been submitted, in similar conditions, to three different feedstocks: standard gasoil (Fig. $8 b$ ), vacuum distillate (Fig. $8 c$ ) and gasoil from vacuum residue conversion unit (Fig. $8 d$ ). Compared to the industrial used catalysts, the main band is always located at about $1600-1605 \mathrm{~cm}^{-1}$, but other bands are present in this region. The vacuum distillate catalyst exhibits bands at 1585 and $1618 \mathrm{~cm}^{-1}$, whereas the two other catalysts exhibit a broad shoulder between 1500 and $1600 \mathrm{~cm}^{-1}$. These supplementary bands could be assigned to intermediate deposit species and can provide information on coke formation mechanism. Between 1250 and $1450 \mathrm{~cm}^{-1}$, bands are weak, inexistent for the standard gasoil catalysts. Two bands at 1345 and $1375 \mathrm{~cm}^{-1}$ are present for the vacuum distillate catalyst.

The precise interpretation of these spectra is a difficult task. Of course, the chemical structure of coke determines the vibrational frequencies. The assignment of bands is often based on comparisons with simple aromatic molecules spectra, such as naphthalene or anthracene: it allows to characterize the topology (chain-like, sheet-like...) of the coke [22]. This approach is powerful for simple reaction such as methanol conversion, but becomes less tractable for complex petroleum feedstocks. Another approach, more valid for catalysts with high coke content, is to consider coke as a defective graphite-like structure. For instance, the position and the number of $\mathrm{G}$ bands can be correlated with the degree of disorder of coke [24]. Moreover, the size of coke clusters can modify the relative intensities of Raman band: for graphite, the intensity ratio $\mathrm{I}_{1355} / \mathrm{I}_{1585}$ increases when the graphite particle size decreases. Such a correlation is assumed to be true for coke on catalyst [20]. Beyond these qualitative aspects, Raman spectrometry have been recently proposed as a quantitative method to measure the amount of coke, during the dehydrogenation of propane on $\mathrm{Cr} / \mathrm{Al}_{2} \mathrm{O}_{3}$ [25]. As a conclusion, Raman spectrometry appears as promising to study the deactivation mechanism of hydrotreating catalyst. Basically, the technique allows to compare the chemical structure of coke deposit on different catalysts. Nevertheless, taking into account the complex composition of hydrotreatment feedstock, more detailed studies are required in order to provide fine descriptions of the structure of coke and its mechanism of formation.

\section{CONCLUSION}

Raman spectrometry provides structural informations on the active components of hydrotreatment catalysis, at the different steps of synthesis. Chemical speciation of metal anions, presence of impurities, formation of crystalline phase, or deposited coke structure have strong effects on catalyst activity and have been studied by Raman spectrometry. All the examples in this paper demonstrate that this technique provides important insights in order to achieve a more rational preparation of hydrotreatment catalyst. In a near future, the development of in situ and spatially resolved Raman characterization will lead to a better understanding of physico-chemical processes involved in catalyst synthesis.

\section{ACKNOWLEDGEMENTS}

The authors thank their colleagues from the Heterogeneous Catalysis Department of IFP, especially C. Bouchy, T. Cseri, 
P. Euzen, B. Guichard, D. Guillaume, M. Roy-Auberger, for providing samples and for their fruitful collaboration to this work. M. Digne thanks S. Loridant (IRC, Villeurbanne) for his technical help and his numerous advices.

\section{REFERENCES}

1 Pelletier, M.J. (2003) Quantitative Analysis Using Raman Spectrometry. Appl. Spectrosc., 57, 20A-42A.

2 Zanier, N. and Pelet, R. (1993) Applications de la Spectrométrie Raman dans l'Industrie Pétrolière. Oil Gas Sci. Technol., 48, 179-306.

3 Smekal, A. (1923) Zür Quantentheorie der Dispersion. Naturwissenschaften, 11, 873-875.

4 Raman, C.V. and Krishnan, K.S. (1928) A New Type of Secondary Radiation. Nature, 121, 501-502.

5 Ertl, G., Knözinger, H. and Weitkamp, J (1999) Preparation of Solids Catalysts. Wiley-VCH, Weinheim.

6 Iwamoto, R. and Grimblot, J. (2000) Influence of Phosphorus on the Properties of Alumina-Based Hydrotreating Catalysts. Adv. Catal., 44, 417-503.

7 Bergwerff, J.A., Visset, T., Leliveld, B.R.G., Rossenaar, B.D., de Jong, K.P. and Weckhuysen, B.M. (2004) Envisaging the Physicochemical Processes during the Preparation of Supported Catalysts: Raman Microscopy on the Impregnation of Mo onto $\mathrm{Al}_{2} \mathrm{O}_{3}$ Extrudates. J. Am. Chem. Soc., 126, 1454814556.

8 Bergwerff, J.A., van der Water, L.G.A., Visset, T., de Peinder, P., Leliveld, B.R.G., de Jong, K.P. and Weckhuysen, B.M. (2005) Spatially Resolved Raman and UV-visible-NIR Spectroscopy on the Preparation of Supported Catalyst Bodies: Controlling the Formation of $\mathrm{H}_{2} \mathrm{PMo}_{11} \mathrm{CoO}_{40}^{5-}$ Inside $\mathrm{Al}_{2} \mathrm{O}_{3}$ Pellets During Impregnation. Chem. Eur. J., 11, 4591-4601.

9 Pope, M.T. (1983) Heteropoly and Isopoly Oxometalates. Springer-Verlag, Berlin.

10 Griboval, A., Blanchard, P., Payen, E., Fournier, M., Dubois, J.L., Bernard, J.R. (1999) On the use of PCo(Ni) $\mathrm{Mo}_{11}$ heteropolyanions for the preparation of alumina supported HDS catalysts. In: Hydrotreatment and hydrocracking of oil fractions, Delmon, B., Froment, G.F. and Grange, P. (Eds.), Elsevier, 361-364.

11 Griboval, A., Blanchard, P., Payen, E., Fournier, M., Dubois, J.L. (1997) Alumina Supported HDS Catalysts Prepared by Impregnation with New Heteroplycompounds. Stud. Surf. Sci. Catal., 106, 181-194.

12 Himero, S., Niiya, H. and Ueda, T. (1997) Raman Studies on the Identification of Isopolymolybdates in Aqueous Solution. Bull. Chem. Soc. Jpn., 70, 631-637.
13 Ostromecki, M.M., Burcham, L.J., Wachs, I.E., Ramani, N. and Ekerdt, J.G., The Influence of Metal Oxide Additives on the Molecular Structures of Surface Tungsten Oxide Species on Alumina: I. Ambient Conditions. J. Mol. Catal. A - Chem., 132, 43-57.

14 Shieh, S.R. and Duffy, T.S. (2002) Raman Spectroscopy of $\mathrm{Co}(\mathrm{OH})_{2}$ at High Pressures: Implications for Amorphization and Hydrogen Repulsion. Phys. Rev. B, 66, 134301.

15 Ohtsuka, H., Tabata, T., Okada, O., Sabatino, L.M.F and Bellussi, G. (1997) A Study on Selective Reduction of NOx by Propane on Co-Beta. Catal. Lett., 44, 265-270.

16 Kasztelan, S., Grimblot, J., Bonnelle, J.P., Payen, E., Toulhoat, $\mathrm{H}$. and Jacquin, Y. (1983) Preparation of Co-Mo- $\gamma-\mathrm{Al}_{2} \mathrm{O}_{3}$ Catalysts by $\mathrm{pH}$ Regulation of Molybdenum Solution. Characterization of Supported Species and Hydrogenation Activities. Appl. Catal., 7, 91-112.

17 Kim, D.S., Segawa, K., Soeya, T. and Wachs, I.E. (1992) Surface Structures of Supported Molybdenum Oxide Catalysts under Ambient Conditions. J. Catal., 136, 539-553.

18 Saleem, S.S. (1987) Infrared and Raman Spectroscopic Studies of the Polymorphic Forms of Nickel, Cobalt and Ferric Molybdates. Infrared Phys., 27, 309-315.

19 Loridant, S., Feche, C., Essayem, N. and Figueras F. (2005) $\mathrm{WO}_{x} / \mathrm{ZrO}_{2}$ Catalysts Prepared by Anionic Exchange: In Situ Raman Investigation from the Precursor Solutions to the Calcined Catalysts. J. Phys. Chem. B, 109, 5631-5637.

20 Espinat, D., Dexpert, D., Freund, E. and Martino, G. (1985) Characterization of the Coke Formed on Reforming Catalysts by Laser Raman Spectrometry. Appl. Catal., 16, 343-354.

21 Li, J., Xiong, G., Feng, Z., Liu, Z., Xin, Q. and Li, C. (2000) Coke Formation during the Methanol Conversion to Olefins in Zeolites Studied by UV Raman Spectroscopy. Micropor. Mesopor. Mat., 39, 275-280.

22 Chua, Y.T. and Stair, P.C. (2003) An Ultraviolet Raman Spectroscopic Study of Coke Formation in Methanol to Hydrocarbons Conversion over Zeolite H-MFI. J. Catal., 213, 39-46.

23 Brown, F.R., Makovsky, L.E., and Rhee K.H. (1977) Raman Spectra of Supported Molybdena Catalysts: II. Sulfided, Used, and Regenerated Catalysts. J. Catal., 50, 385-389.

24 Robertson, J. (2002) Diamond-like amorphous carbon. Mater. Sci. Eng. R, 37, 129-281.

25 Tinnemans, S.J., Kox, M.H.F., Nijhuis, T.A., Visser, T. and Weckhuysen, B.M. (2005) Real Time Quantitative Raman Spectroscopy of Supported Metal Oxide Catalysts without the Need of an Internal Standard. Phys. Chem. Chem. Phys., 7, 211-216.

Final manuscript received in November 2005 